\title{
No change in common cuckoo Cuculus canorus parasitism and great reed warblers' Acrocephalus arundinaceus egg rejection after seven decades
}

\begin{tabular}{|c|c|}
\hline Journal: & Journal of Avian Biology \\
\hline Manuscript ID: & JAV-00673.R2 \\
\hline Wiley - Manuscript type: & Research \\
\hline Date Submitted by the Author: & $\mathrm{n} / \mathrm{a}$ \\
\hline Complete List of Authors: & $\begin{array}{l}\text { Zölei, Aniko; Eötvös Loránd University, Department of Systematic Zoology } \\
\text { and Ecology } \\
\text { Bán, Miklos; University of Debrecen, MTA-DE-Lendület Behavioural Ecology } \\
\text { Research Group, Department of Evolutionary Zoology } \\
\text { Moskat, C.; Hungarian Natural History Museum, MTA-ELTE-MTM Ecology } \\
\text { Research Group }\end{array}$ \\
\hline Keywords: & Brood parasitism, Arms race, Evolutionary equilibrium \\
\hline Abstract: & $\begin{array}{l}\text { The coevolutionary process among avian brood parasites and their hosts } \\
\text { involves stepwise changes induced by the antagonistic selection pressures } \\
\text { of one on the other. As long-term data on an evolutionary scale is almost } \\
\text { impossible to obtain, most studies can only show snapshots of such } \\
\text { processes. Information on host behaviour, such as changes in egg rejection } \\
\text { rates and the methods of rejection are scarce. In Hungary there is an } \\
\text { interesting case between the common cuckoo (Cuculus canorus) and the } \\
\text { great reed warbler (Acrocephalus arundinaceus), where the level of } \\
\text { parasitism is unusually high (around } 50 \% \text { ). We compared host rejection } \\
\text { rates and methods of rejection from within our own project to that of an } \\
\text { early study carried out and published almost } 70 \text { years ago in the same } \\
\text { region. Our comparisons revealed high and stable rates of parasitism } \\
\text { (range: } 52-64 \% \text { ), and marked fluctuations in the ratio of multiply } \\
\text { parasitized nests (range: } 24-52 \% \text { ). No difference was revealed in egg } \\
\text { rejection rates after } 7 \text { decades ( } 34-39 \% \text { ). Linear mixed-effects modelling } \\
\text { revealed no year effect on the type host responses toward the parasitic } \\
\text { egg(s) during the years of study (categorized as acceptance, ejection, } \\
\text { burial, and nest desertion). Cuckoo egg rejection was primarily affected by } \\
\text { the type of parasitism, as more cuckoo eggs were rejected during single } \\
\text { parasitism than from multiply parasitized nests. Our comparison did not } \\
\text { reveal any directional changes in this cuckoo-host relationship, except a } \\
\text { slight decrease in the frequency of multiple parasitism, which is likely to be } \\
\text { independent from coevolutionary processes. }\end{array}$ \\
\hline
\end{tabular}


SCHOLARONE $^{m}$
Manuscripts

Page 1 of $24 \quad$ Journal of Avian Biology

Manuscripts
Mant

$(2)$ 
1 No change in common cuckoo Cuculus canorus parasitism

2 and great reed warblers' Acrocephalus arundinaceus egg

3 rejection after seven decades

4

5

6 Anikó Zölei · Miklós Bán · Csaba Moskát

7

8 A. Zölei, Dept. Syst. Zool. and Ecol., Eötvös Lóránd Univ., Pázmány Péter sétány

9 1/C., H-1117 Budapest, Hungary. - M. Bán, MTA-DE "Lendület" Behav. Ecol. Res.

10 Grp., Dept. of Evol. Zool., Univ. of Debrecen, Egyetem tér 1, H-4032 Debrecen,

11 Hungary. - C. Moskát (moskat@nhmus.hu), MTA-ELTE-MTMEcol.Res.Grp.,

12 Hungarian Academy of Sciences, clo Biol. Inst., Eötvös Lóránd University, Pázmány

13 Péter sétány 1/C., H-1117 Budapest and Hungarian Natural History Museum, Baross

14 u. 13., H-1088 Budapest, Hungary

15

16

17 Word count: 6,939

18

19 Keywords Brood parasitism - Arms race $\cdot$ Evolutionary equilibrium · Long-term

20 changes $\cdot$ Adaptations
21

22 
24 The coevolutionary process among avian brood parasites and their hosts involves 25 stepwise changes induced by the antagonistic selection pressures of one on the other.

26 As long-term data on an evolutionary scale is almost impossible to obtain, most studies can only show snapshots of such processes. Information on host behaviour, such as changes in egg rejection rates and the methods of rejection are scarce. In Hungary there is an interesting case between the common cuckoo (Cuculus canorus) and the great reed warbler (Acrocephalus arundinaceus), where the level of parasitism is unusually high (around 50\%). We compared host rejection rates and methods of rejection from within our own project to that of an early study carried out and published almost 70 years ago in the same region. Our comparisons revealed high and stable rates of parasitism (range: 52-64\%), and marked fluctuations in the ratio of multiply parasitized nests (range: $24-52 \%$ ). No difference was revealed in egg rejection rates after 7 decades (34-39\%). Linear mixed-effects modelling revealed no year effect on the type host responses toward the parasitic egg(s) during the years of study (categorized as acceptance, ejection, burial, and nest desertion). Cuckoo egg rejection was primarily affected by the type of parasitism, as more cuckoo eggs were rejected during single parasitism than from multiply parasitized nests. Our comparison

41 did not reveal any directional changes in this cuckoo-host relationship, except a slight

42 decrease in the frequency of multiple parasitism, which is likely to be independent from coevolutionary processes. 
Avian brood parasitism by the common cuckoo (Cuculus canorus; hereafter cuckoo) severely reduces host fitness (Davies 2000, Hauber and Dearborn 2003). A successful parasitic event causes the total loss of the host's current breeding success, as the cuckoo chick evicts the rest of the clutch or brood (Honza et al. 2007, Anderson et al. 2009). Raising the parasite offspring may take up the whole breeding season of the host (Davies 2000), and potentially impose future fitness costs. Within this scenario, an evolutionary arms race may occur (Dawkins and Krebs 1979, Davies and Brooke 1989, Moksnes et al. 1991). Some authors suggest that the arms race could be cyclic, where periods of adaptation and no adaptation may follow each other (Soler et al. 1998). This is facilitated by asymmetries in local selective pressures (Gandon et al 2008), where subpopulations are surrounded by varied environmental factors, thus creating dissimilar sets of adaptive traits among subpopulations. This in turn results in a greater phenotypic and genotypic diversity for the overall population (Thompson et al. 2002). As shown by another study on the great spotted cuckoo (Clamator glandarius) and its magpie (Pica pica) host at a small geographic scale (MartinGálvez et al 2007, Soler et al. 2013), this creates appropriate conditions for mosaic coevolution. This theory predicts that several parameters of brood parasitism, e.g. parasitism rate and host defence (egg rejection), covary with within-plot productivity of hosts, so individuals with highly evolved antiparasite defence ability may occupy the best plots with a high risk of parasitism. In this process, cuckoos abandon a host population where antiparasite defences are well developed, but may recolonize it when antiparasite defences are lowered. During the arms race, the hosts' abilities to reduce the cost of parasitism and the parasites' abilities to trick the host into raising its offspring are competing with each other (Røskaft and Moksnes 1998, Takasu 1998, Davies 2000, Krüger 2007), resulting in monotonous gains or oscillating changes in trait values on both sides (Rothstein 1990, Takasu 2003). Others put forward the equilibrium hypothesis, according to which interacting factors are making longstanding coexistence between host and parasite feasible (for an overview see Lotem and Nakamura 1998). Acceptance of the parasite offspring can also be viewed as a consequence of insufficient evolutionary time for a more adaptive response to occur and spread in the host population (the time lag theory: Lotem and Nakamura 1998).

The most effective mechanism for host defence is based on egg recognition (Rothstein 1975, Moksnes et al 1991, Hauber and Sherman 2001, Hauber et al. 2006), which, in turn, can propel an increasing level of egg mimicry on behalf of the parasite 
80 (Davies 2000). Krüger et al. (2009) showed that speciation in parasitic cuckoos is 81 faster than that of their non-parasitic relatives, but there is no empirical evidence on the speed of coevolution. There are examples of population-level adaptations over relatively short periods of time (Takasu et al. 1993, Avilés et al 2006). If the hosts' evolutionary potential allows for it, hosts' adaptations sooner or later win the arms race and old host species are abandoned. A good example is the red-backed shrike (Lanius collurio), which used to be a favoured cuckoo host in Hungary but was abandoned when red-backed shrikes developed such a high-level of egg discrimination ability that parasite eggs were rejected in $93.3 \%$ of cases (Lovászi and Moskát 2004; for other cases see Davies and Brooke 1989, Moksnes and Røskaft 1992, Honza et al. 2004, Procházka and Honza 2004, Yang et al. 2014a). Egg rejection behaviour may be retained in the absence of parasitism (Lahti 2006), even for millions of years (e.g. Peer et al. 2011), although it may also show deficiency in time in the lack of brood parasitism compared to parasitized populations (Yang et al. 2014b). The speed of coevolution in parasites and their hosts seems to be primarily affected by population dynamics (Soler et al. 1998, Gandon et al. 2008) and habitat structure (Røskaft et al. 2002). New hosts are 'conquered' within a few centuries or even decades (Takasu et al. 1993), and parasite egg appearance might be matched relatively quickly to that of the host (Avilés et al. 2006). However, the arms race model is often oversimplified (Lotem and Nakamura 1998) and the lack of historical data makes it difficult to evaluate the different stages on an evolutionary time scale. Consequently, there is the need for long-term field studies, which may provide additional pieces to the coevolutionary puzzle among hosts and brood parasites (Møller and Soler 2012).

Recent studies revealed that cuckoos may know the appearance of their eggs, and females try to increase egg matching with active selection of the host nest (Avilés et al. 2006, Cherry et al. 2007a, Honza et al. 2014, but see Antonov et al. 2012). In contrast, cuckoos do not seem to distinguish between cuckoo and great reed warbler eggs when removing one egg from the host clutch. Cuckoo females randomly take one egg from the nest (Davies and Brooke 1988, Moskát and Honza 2002) and this implies that their offspring may be evicted along with the host's offspring by another, earlier hatching cuckoo chick. Despite the fact that multiple parasitism is thought to be generally rare in the cuckoo-host system, it can reach high levels in Hungary, as about $36 \%$ of the parasitized nests contained 2-4 cuckoo eggs (Moskát and Honza 
114 2002). Multiple parasitism results from repeated parasitic events by different cuckoo 115 females (Moskát et al. 2009).

116 Egg discrimination ability of hosts is affected by several factors (Davies 2000, 117 Stokke et al. 2007) and may be characteristic of a host population. For example, the 118 duration of parasitism and stage in the arms race (Davies and Brooke 1989, Davies 119 2000), host age (Lotem et al. 1992, Strausberger and Rotshtein 2009, Molina-Morales 120 et al. 2014, Moskát et al. 2014), stage of breeding (Moskát et al. 2014), stage of 121 season (Lotem et. al 1992), and multiple parasitism (Moskát et al. 2009, Gloag et al. 122 2014) are such factors. Egg rejection behaviour in cuckoo hosts may have a genetic 123 background (Martin-Gálvez et al. 2006), so hosts may retain egg rejection abilities 124 after parasitism is terminated (e.g. Honza et al. 2004, Lovászi and Moskát 2004, Lahti 2006). Cuckoo hosts may also retain their egg rejection ability when they are introduced into parasite-free areas (Soler and Møller 1990,Yang 2014a). Alternatively, defence can be based on phenotypic plasticity, where hosts may quickly reduce their egg rejection ability when parasitism is declining (Thorogood and Davies 2013). If the distribution of parasitism within a population is non-random, this may affect the hosts' resistance to parasitism, and host lineages might develop different antiparasite defence levels within the same population (Grim 2002, Hoover et al. 2006, Martín-Gálvez et al. 2007, Soler et al. 2013).

We studied the characteristics of cuckoo parasitism on great reed warblers

134 (Acrocephalus arundinaceus) in the Hungarian Great Plain. We compared our current 135 data with long-term (<70 yrs; Molnár 1944) and short-term results (< 10 yrs; Moskát 136 and Honza 2002) published for the same population to seek detectable changes in the 137 rate of parasitism or host reactions. Although these data sets are only snap-shots of the 138 long-term cuckoo-host coevolutionary relationship, such data sets are rare. We 139 hypothesized that an increase in antiparasite defence, as a consequence of an 140 escalating coevolutionary arms race between cuckoos and their hosts, changed hosts 141 from unconditional acceptors in the incidences of new parasitism toward being strong 142 rejecters (c.f. Davies 2000). In this framework, we predict higher rejection rates of 143 cuckoo eggs in the most recent data set than in the old data. Alternatively, we predict 144 no change in hosts' antiparasitic defence if the cuckoo-host relationship is at 145 equilibrium (sensu Brooker and Brooker 1996, Lotem and Nakamura 1998, Takasu 146 1998). 
148

149

150

151 We carried out fieldwork in 2006 and 2007, in the surroundings of Kiskunlacháza

$152\left(47^{\circ} 19^{\prime} \mathrm{N} ; 19^{\circ} 05^{\prime} \mathrm{E}\right)$ and Apaj $\left(47^{\circ} 07^{\prime} \mathrm{N} ; 1^{\circ} 06^{\prime} \mathrm{E}\right)$, ca. $50 \mathrm{~km}$ south of Budapest,

153 Hungary. Fieldwork started in mid-May and finished in late June, when great reed

154 warblers and cuckoos were still active, but with few new nests being built in the area.

155 Great reed warblers bred in channel-side reed beds, i.e. 2-5 m wide long reed strips

156 (Figure 1). Typically, there are different tree species (mainly Salix and Populus spp.)

157 along the channels that serve as vantage points for cuckoos, together with pylons and

158 power lines, when searching for nests (Moskát and Honza 2000).

159

160

161

162

163

164

165

166

167

168

169

170

171

172

173

174

175

176

177

178

179

180
As a fine example of meticulously documented early investigation of the cuckoo-host system, Molnár (1944) started collecting data in the reed beds of the oxbow lakes of the River Körös near the town Szarvas (46 $\left.{ }^{\circ} 52^{\prime} \mathrm{N} ; 2^{\circ} 33^{\prime} \mathrm{E}\right)$ in 1935 , and worked there until 1944. We also used his original field notes for details. His data set suffered from fluctuating research intensity, and in certain years experiments dominated over observations on the natural host-brood parasite system. For this reason, we selected three years' data between 1940 and 1942, when sample sizes were large and suitable for comparison, i.e. daily nest checking was done on nonexperimental nests. Unfortunately, this study site has been mainly degraded, as banks were built-in by summer cottages and the majority of the reed-beds were removed (Lilla Barabás, in litt.). For this reason, we carried out our research at Apaj, and also used results of cuckoo parasitism on great reed warblers at Apaj from the years 1998northwest from Molnár's study site, where cuckoos and great reed warblers were also abundant. The 1998-99 sites greatly overlapped with our 2006-2007 study sites, and also included adjacent channels with similar habitats. Such small geographical shifts are necessary because some sections of the habitat suffer from year-to-year channel dredging). As most of the reed beds are connected or close to each other in Hungary, and there is no geographic barrier among the breeding sites of this species, all great reed warblers can be regarded as members of one interbreeding population. Genetic analysis revealed high similarity of breeding great reed warblers in different 99 published by Moskát and Honza (2002). The latter study was carried out ca. $80 \mathrm{~km}$ perturbations (e.g. poisoning and reed cutting, air pollution caused by heavy traffic, 
181 parts of the Hungarian Great Plain at large distances (130 km) (Moskát et al. 2008),

182 although the population is not homogeneous (Mátrai et al. 2012). In a previous study

183 at three sites in Hungary similar rejection rates were revealed in great reed warblers'

184 egg rejection (Moskát et al. 2008), suggesting that the two sites included in this study

185 are unlikely to confound the results.

186

187

188

189

190

191

rejection as (a) ejection; (b) desertion of the nest or (c) burial of the cuckoo egg (when

192 Cuckoo females always remove one egg from the clutch they parasitize and great reed

193 warblers lay one egg each day until clutch completion. This allows the recording of

194 the most likely scenario on the daily visits (i.e. clutch size increased by one host egg:

195 no parasitic event; clutch size remaining constant before clutch completion: parasitic

196 event followed by ejection; clutch size remaining constant with one parasite egg:

197 parasitic event without ejection etc.) A previous study revealed that great reed

198 warblers more readily accept cuckoo eggs in multiply parasitized nests than in cases

199 of single parasitism (Moskát et al. 2009), so we analyzed host responses to parasitism

200 regarding the type of parasitism (single or multiple).

$201 \quad$ Although rejection cost (mistakenly ejected or destroyed host egg(s) ejected

202 together with the cuckoo egg) and recognition error (mistakenly ejected host egg(s)

203 with the cuckoo egg remaining in the nest) would be informative on the level of egg

204 rejection ability of the hosts, we did not compare them due to uncertainty in Molnár's

205 data. It was difficult to distinguish recognition errors from partial predation, so we did

206 not find it useful for this purpose. Great reed warblers seem to make these errors

207 rarely, as we found clear cases of rejection costs two times (the costs of one or two

208 great reed warbler eggs), and three times in case of recognition errors (one great reed

209 warbler egg was missing in each case) in the Molnár dataset. For more recent data see

210 Moskát and Honza (2002).

211

212 Statistical analyses

213 
214 We used linear mixed-effects modelling with SPSS version 17.0 (SPSS Inc., Chicago,

215 IL, USA) to evaluate the effects of 'type' (single/multiple parasitism) as a fixed factor

216 on 'host response to parasitism' as a dependent variable. In our models, the dependent

217 variable either was binary (acceptance or rejection of the cuckoo egg) or categorical

218 (after a six-day control period acceptance, ejection, desertion and burial; see Moskát

219 and Honza 2002 for more details of host responses). Linear mixed-effects models

220 were useful to avoid pseudoreplication in data (Bolker et al. 2009, Nakagawa and

221 Hauber 2011). As we analysed host responses to parasitism on the basis of individual

222 cuckoo eggs, we considered nest ID as a random (subject) factor; and cuckoo egg ID

223 as a repetition in the model. We also used SPPS version 17.0 for other statistical

224 comparisons (linear regression, chi-square test).

225

226

227

228

229

230

231

232

233

234

235

236

237

238

239

240

241

242

243

244

245

246

\section{Results}

Parasitism rate was high and stable in all three periods compared (range: $52-64 \%, \mathrm{n}_{\text {tot }}$ $=671$ nest; $\chi^{2}{ }_{6}=11.854, \mathrm{P}=0.065$; Table 1 ; Figure 2 ). A high proportion of parasitic eggs was found in multiply parasitized nests in this population (range: $45-58 \%, \mathrm{n}_{\text {tot }}=$ 541 cuckoo eggs). Multiple parasitism (range: $24-52 \%, \mathrm{n}_{\text {tot }}=368$ parasitized nests; Tables 1 and 2) was slightly lower in the current as compared to the historical samples $\left(\chi_{6}^{2}=12.943, \mathrm{P}=0.044\right)$. Host responses to parasitism (acceptance/rejection) did not differ significantly among the sampled periods (range of rejection rates: $34-45 \%, \mathrm{n}_{\text {tot }}$ $=376$ cuckoo eggs; Table 3 and Figure 2; for all cases: $\chi_{3}^{2}=4.324, \mathrm{P}=0.115$ ), neither in single $\left(\chi_{3}^{2}=2.439, \mathrm{P}=0.295\right)$ or multiple parasitism $\left(\chi_{3}^{2}=2.844, \mathrm{P}=0.241\right)$.

Linear mixed-effects modelling revealed that host egg rejection behaviour (accept or reject) was affected only by the type of parasitism (single/multiple: $\mathrm{F}_{1,388}=$ $12.470, \mathrm{P}<0.001$ ). This means that hosts are less likely to escape brood parasitism by ejecting the cuckoo egg when the nest contains only one parasitic egg. Year did not affect great reed warblers' egg discrimination $\left(\mathrm{F}_{6,299}=1.739, \mathrm{P}=0.112\right)$. When the interaction of year $x$ type of parasitism was included the interaction term was nonsignificant $\left(\mathrm{F}_{6,367}=1.443, \mathrm{P}=0.197\right)$, and other effects remained the same (type of parasitism: $F_{1,392}=5.348, P=0.21$; year: $\left.F_{6,367}=1.993, P=0.066\right)$. The effect of time and type remained similar when we used the dependent variable (rejection categories) 
separately, i.e. ejection, desertion and burial (type of parasitism: $\mathrm{F}_{1,377}=8.469, \mathrm{P}=$ 0.004 ; year: $\mathrm{F}_{6,258}=1.378, \mathrm{P}=0.224$ ).

\section{Discussion}

Our results revealed no difference in the rate of parasitism and host responses to cuckoo eggs among the data sets (1940-1942: Molnár 1944, 1998-1999: Moskát and Honza 2002 and 2006-2007: present study). This is surprising, given that hosts may gain high-level adaptations against brood parasitism in relatively short time frames. For example, in central Japan a new cuckoo parasitism started on azure-winged magpies (Cyanopica cyana) in the 1970s (Yamagishi and Fujioka 1986), when this host did not show effective rejection toward parasitic eggs, but under the high parasitic pressure their defence developed quickly and they learned to reject eggs of the common cuckoo within two decades from the onset of parasitism (Nakamura et al. 1998; H. Nakamura pers. com.). However, in that population parasite egg mimicry did not change accordingly (Takasu et al. 2009). Soler and Møller (1990) also reported a rapid increase of antiparasite defence in a magpie ( $P$ ica pica) population in Spain, where the distribution area of the great spotted cuckoo (Clamator glandarius) became overlapping with this host species. However, this overlap may also have had occurred previously. In this relationship, antiparasite defence levels increased significantly in both natural and experimental parasitism (Soler et al. 1994, Soler and Soler 2000). The main difference between any of these examples and our case is that we studied an existing host-brood parasite relationship, not a newly formed one. The speed of adaptations may depend on several factors, e.g. the stage of the coevolutionary process (Takasu et al. 2009); the incidence level of parasitism (Røskaft et al. 2002), or gene transfer from nearby populations (Martín-Gálvez et al. 2007, Soler et al. 2001).

Egg discrimination is an important antiparasite defence mechanism in the great reed warbler (Moskát et al. 2009, Pozgayová et al. 2011). In several cuckoo host species nest guarding may also be a defence mechanism (e.g. Welbergen and Davies 2009). Experimental studies revealed that great reed warblers frequently attack stuffed cuckoos (Bártol et al. 2002) and model cuckoos (Honza et al. 2006) at their nests in our study area. However, the efficiency of this frontline defence is questionable, as we observed several times that when parasitizing cuckoos were driven away by hosts, 
281 they came back to the same nest several times within the next 24 hours and so the 282 attempts eventually resulted in successful parasitism (C. Moskát, unpublished).

283 Interestingly, egg discrimination and nest defence did not correlate in the great reed 284 warbler (Trnka and Grim 2014), as different cognitive mechanisms are responsible for 285 these two types of defence. Unfortunately, we had no quantitative data on hosts' 286 aggression toward cuckoos from the 1940-1942 period to compare with recent data, 287 but Molnár (1944) observed several cases when great reed warblers attacked cuckoos 288 heavily.

Cuckoo parasitism is costly for the hosts, as the young cuckoo chicks evict 291 host population is likely to be a sink under such a high parasitic pressure. A wellconnected metapopulation structure of the host species with a high carrying capacity

293 of brood parasitism (potentially including allopatry with the cuckoo) could be one of

294 the possible solutions to stabilize this system. Simulations revealed that if naive 295 individuals with poor egg discrimination ability immigrate every year, it may slow 296 down the antiparasite adaptation of the host population (Barabás et al. 2004). The 297 immigration of hosts seems to be important in stabilizing our host-brood parasite 298 relationship that would go extinct quickly without this process as the consequence of 299 the heavy brood parasitism. The immigration of naïve individuals into our study area 300 may slow down the evolution of adaptations. As shown by another study on the great 301 spotted cuckoo and its magpie host at a similar geographic scale (Martin-Gálvez et al 302 2007, Soler et al. 2013), this creates appropriate conditions for mosaic coevolution. It 303 was also suggested that rejection and acceptance are better explained by genetic rather 304 than by geographical distances among subpopulations (Soler et al. 2001).

305 As female cuckoos lay one egg per host nest (Moskát and Honza 2009), 306 multiple parasitism only occurs when the availability of appropriate nests is low. The 307 unusually high parasitism rate with high proportions of multiply parasitized nests is a 308 unique characteristic of the Hungarian cuckoo-great reed warbler relationship. As our 309 study revealed, about half of the cuckoo eggs can be found in multiply parasitized 310 nests. Even though we cannot exclude the possibility that this reflects an adaptation in 311 cuckoos, the decrease in multiple parasitism in 70 years can signal a decrease in 312 'parasite load' which might be independent from co-evolutionary processes linking 313 hosts and brood parasites. It may simply be the consequence of changes in the habitat 
314 resulting in differential dispersion of hosts and/or cuckoos, or changes in cuckoo

315 population density for reasons so far unbeknownst to us.

316 Clutch characteristics are expected to show lower variation in an advanced

317 stage of the arms race than in undeveloped stages (Moksnes and Røskaft 1995, Øien

318 et al. 1995, Stokke et al. 1999, 2005), as rejection is driving intra-clutch variation

319 down to a very low level. As appropriate data on clutch appearances from the studied

320 historical period are lacking, we could not evaluate whether intra-clutch variation

321 changed in the last 70 years in our host-brood parasite relationship. Recent

322 spectrophotometric studies in single parasitism revealed that although mimicry is an

323 important factor in egg discrimination (Igic et al. 2012, Moskát et al. 2012), higher,

324 not lower, intra-clutch variation facilitated egg rejection in our hosts (Cherry et al.

325 2007b).

326

Compared to generalist brood parasites, a more advanced stage in the arms

328 race model is expected to be found among the specialist cuckoos and their hosts (e.g.

329 Dawkins and Krebs 1979, Davies and Brooke 1989, Moksnes et al. 1991, Davies

330 2000, Takasu 1998, Krüger 2007). For the brown-headed cowbird, another well-

331 studied brood parasite of the Northern hemisphere, the time lag and evolutionary

332 equilibrium hypotheses seem to be more generally suited (Lotem and Nakamura 1998,

333 Rothstein and Robinson 1998). However, egg discrimination in the generalist cowbird

334 system has developed in only a small number of host species than among cuckoo

335 hosts (Rothstein and Robinson 1998, Davies 2000).

336 We compared basic characteristics of cuckoo parasitism on great reed warblers

337 in a long-term (about seven decades) and a short-term (almost one decade) view and

338 the most important antiparasitic defence adaptation of hosts, the egg rejection

339 behaviour. However, a future study should investigate the changes of cuckoo egg

340 mimicry in the last seven or more decades. Although we had no exact data for several

341 decades from the intervening period, ornithological notes on the continuously high

342 cuckoo parasitism rate on this host (Moskát and Honza 2002, Egon Schmidt in litt.) is

343 suggestive of a temporary equilibrium instead of a time lag with a stable rate of

344 parasitism and hosts' antiparasite level. 
347 Acknowledgements The study was supported by the Hungarian Scientific Research 348 Fund (OTKA, No. T83210) to CM. The Duna-Ipoly and Kiskunság National Parks

349 provided permissions for research. The authors are thankful to Eivin Røskaft, Anders 350 P. Møller, Jesus M. Avilés, Michael I. Cherry, Márk E. Hauber, Marcel Honza, Rita 351 Hargitai, Nikoletta Geltsch, and István Zsoldos for consultation or their help in the 352 fieldwork. Linguistic corrections were kindly provided by Kate McKenzie and Paul 353 Reid.

354

355

356

357

358

359

360

361

362

363

364

365

366

367

368

369

370

371

372

373

374

375

376

377

378

379

380

\section{References}

Anderson, M. G., Moskát, C., Bán, M., Grim, T., Cassey, P. and Hauber, M.A. 2009. Egg eviction imposes a recoverable cost of virulence in chicks of a brood parasite. - PLoS ONE 4, e7725

Antonov, A., Stokke, B. G., Fossøy, F., Ranke, P.S., Liang, W., Yang, C., Moksnes, A., Shykoff, J. and Røskaft, E. 2012. Are cuckoos maximizing egg mimicry by selecting host individuals with better matching egg phenotypes? - PLoS ONE 7. e31704

Avilés, J. M., Moskát, C., Bán, M., Hargitai, R. and Parejo, D. 2009. Common cuckoos (Cuculus canorus) do not rely on indicators of parental abilities when searching for host nests: the importance of host defences. - Auk 126: 431-438,

Avilés, J. M., Stokke, B. G., Moksnes, A., Røskaft, E., Asmul, M. and Møller, A. P. 2006. Rapid increase in cuckoo egg matching in a recently parasitized reed warbler population. - J. Evol. Biol. 19: 1901-1910.

Barabás, L., Gilicze, B., Takasu, F. and Moskát, C. 2004. Survival and anti-parasite defense in a host metapopulation under heavy brood parasitism: a source-sink dynamic model. - J. Ethol. 22: 143-151.

Bártol, I., Karcza, Z., Moskát, C., Røskaft, E. and Kisbenedek, T. 2002. Responses of great reed warblers Acrocephalus arundinaceus to experimental brood parasitism: the effects of a cuckoo Cuculus canorus dummy and egg mimicry. - J. Avian Biol. 33: 420-425.

Bolker, B. M., Brooks, M. E., Clark, C. J., Geange, S. W., Poulsen, J. R., Stevens, M. H. H. and White, J. S. S. 2009. Generalized linear mixed models: a practical guide for ecology and evolution. - Trends Ecol. Evol. 24: 127-135. 
381 Brooker, M. and Brooker, L. 1996. Acceptance by the splendid fairy-wren of

382

383

384

385

386

387

388

389

390

391

392

393

394

395

396

397

398

399

400

401

402

403

404

405

406

407

408

409

410

411

412

413 parasitism by Horsfield's bronze-cuckoo: further evidence for evolutionary equilibrium in brood parasitism. - Behav. Ecol. 7: 395-407.

Cherry, M. I., Bennett, A. T. D. and Moskát, C. 2007a. Do cuckoos choose nests of great reed warblers on the basis of host egg appearance? - J. Evol. Biol. 20: 1218-1222.

Cherry, M. I., Benneth, A. T. D. and Moskát, C. 2007b. Host intra-clutch variation, cuckoo egg matching and egg rejection by great reed warblers. - Naturwiss. 94: 441-447.

Davies, N. B. 2000. Cuckoos, cowbirds and other cheats. - T and AD Poyser, London.

Davies, N. B. and Brooke, M. de L. 1988. Cuckoos versus reed warblers: adaptations and counteradaptations. - Anim. Behav. 36: 262-284.

Davies, N. B. and Brooke, M. de L. 1989. An experimental study of co-evolution between the cuckoo, Cuculus canorus, and its hosts. II. Host egg markings, chick discrimination and general discussion. - J. Anim. Ecol. 58:.225-236.

Dawkins, N. B. and Krebs, J. R. 1979. Arms races between and within species. - Proc. R. Soc. B 205:489-511.

Gandon, S., Buckling, A., Decaestecker, E. and Day, T. 2008. Host-parasite coevolution and patterns of adaptation across time and space. - J. Evol. Biol. 21:1861-1866.

Gloag, R., Fiorini, V. D., Reboreda, J. C. and Kacelnik, A. 2014. Shiny cowbirds share foster mothers but not true mothers in multiply parasitized mockingbird nests. - Behav. Ecol. Sociobiol. 68: 681-689.

Grim, T. 2002. Why is mimicry in cuckoo eggs sometimes so poor? - J. Avian. Biol. 33: 302-305.

Hauber, M. E. and Dearborn, D. C. 2003. Parentage without parental care: what to look for in genetic studies of obligate brood-parasitic mating systems. - Auk 120: 1-13.

Hauber, M. E. and Sherman, P. W. 2001. Self-referent phenotype matching: theoretical considerations and empirical results. - Trends. Neurosci. 24: 609616.

Hauber, M. E, Moskát, C. and Bán, M. 2006. Experimental shift in hosts' acceptance threshold of inaccurate-mimic brood parasite eggs. - Biol. Lett. 2: 177-180. 
414

415

416

417

418

419

420

421

422

423

424

425

426

427

428

429

430

431

432

433

434

435

436

437

438

439

440

441

442

443

444

445

446

Honza, M., Sicha, V., Procházka, P. and Lezalová, R. 2006. Host nest defense against a color-dimorphic brood parasite: great reed warblers (Acrocephalus arundinaceus) versus common cuckoos (Cuculus canorus). - J. Ornithol. 147: 629-637.

Honza, M., Procházka, P., Stokke, B. G., Moksnes, A., Røskaft, E., Capek, M. Jr and Mrlík, V. 2004. Are blackcaps current winners in the evolutionary struggle against the common cuckoo? - J. Ethol. 22: 175-180.

Honza, M., Šulc, M., Jelínek, V., Požgayová, M. and Procházka, P. 2014. Brood parasites lay eggs matching the appearance of host clutches. - Proc. R. Soc. B 281: 20132665.

Honza, M., Voslajerová, K. and Moskát, C. 2007. Eviction behaviour of the common cuckoo Cuculus canorus chicks. - J. Avian. Biol. 38: 385-389.

Hoover, J. P., Yasukawa, R. and Hauber, M. E. 2006. Spatially and temporally structured avian brood parasitism affects the fitness benefits of hosts' rejection strategies. - Anim. Behav. 72: 881-890.

Igic, B., Cassey, P., Grim, T., Greenwood, D. R., Moskát, C., Rutila, J. and Hauber, M. E. 2012. A shared chemical basis of avian host-parasite egg colour mimicry. - Proc. R. Soc. B 279: 1068-1076.

Kleven, O., Moksnes, A., Røskaft, E. and Honza, M. 1999. Host species affects the growth rate of cuckoo (Cuculus canorus) chicks. - Behav. Ecol. Sociobiol. 47: 41-46.

Krüger, O. 2007. Cuckoos, cowbirds and hosts: adaptations, trade-offs and constraints. - Phil. Trans. R. Soc. B 362: 1879-1886.

Krüger, O., Sorenson, M. D. and Davies, N.B. 2009. Does coevolution promote species richness in parasitic cuckoos? - Proc. R. Soc. Lond. B 276: 3871-3879.

Lahti, D. C. 2006. Persistence of egg recognition in the absence of cuckoo brood parasitism: pattern and process. - Evolution 60: 157-168.

Leisler, B. and Schulze-Hagen, K. 2011. The Reed Warblers - diversity in a uniform bird family. - KNNV Publishing, Zeist .

Lotem, A. and Nakamura, H. 1998. Evolutionary equilibria in avian brood parasitism. An alternative to the "arms race-evolutionary lag" concept. In: Rothstein SI, Robinson SK (eds) Parasitic birds and their hosts. Studies in coevolution. Oxford University Press, New York. 
447

448

449

450

451

452

453

454

455

456

457

458

459

460

461

462

463

464

465

466

467

468

469

470

471

472

473

474

475

476

477

478

Lotem, A., Nakamura, H. and Zahavi, A. 1992. Rejection of cuckoo eggs in relation to host age: a possible evolutionary equilibrium. - Behav. Ecol. 3: 128-132.

Lovászi, P. and Moskát, C. 2004. Break-down of arms race between the red-backed shrike (Lanius collurio) and common cuckoo (Cuculus canorus). - Behaviour 141: 245-262.

Martín-Gálvez, D., Soler, J. J., Martínez, J. G., Krupa, A. P., Richard, M., Soler, M., Møller, A. P. and Burke, T. 2006. A quantitative trait locus for recognition of foreign eggs in the host of a brood parasite. - J. Evol. Biol. 19: 543-550.

Martín-Gálvez, D., Soler, J. J., Martínez, J. G., Krupa, A. P., Soler, M. and Burke, T. 2007. Cuckoo parasitism and productivity in different magpie subpopulations predict frequencies of the $457 \mathrm{bp}$ allele: a mosaic of coevolution at a small geographic scale. - Evolution 61: 2340-2348.

Mátrai, N., Bakonyi, G., Gyurácz, J., Hoffmann, G., Raijmakers, K., Neto, J.M. and Mátics, R. 2012. Do the European great reed warblers (Acrocephalus arundinaceus) reach South Africa during wintering? - J. Ornithol. 153: 579583.

Moksnes, A. and Røskaft, E. 1992. Responses of some rare cuckoo hosts to mimetic model cuckoo eggs and to foreign conspecific eggs. - Ornis Scand. 23:17-23.

Moksnes, A. and Røskaft, E. 1995. Egg-morph and host preferences in the common cuckoo (Cuculus canorus): an analysis of cuckoo and host eggs from European museum collections. - J. Zool. 236: 625-648.

Moksnes, A., Røskaft, E., Braa, A. T., Korsnes, L., Lampe, H. M. and Pedersen, H. C. 1991. Behavioural responses of potential hosts towards artificial cuckoo eggs and dummies. - Behaviour 116: 64-89.

Moksnes, A., Røskaft, E., Rudolfsen, G., Skjelseth, S., Stokke, B. G., Kleven, O., Gibbs, H.L., Honza, M., Taborsky, B.. Teuschl, Y., Vogl, W. and Taborsky, M. 2008. Individual female common cuckoos Cuculus canorus lay constant egg types but egg appearance cannot be used to assign eggs to females. - J. Avian Biol. 39: 238-241.

Molina-Morales, M., Martínez, J. G., Martín-Gálvez, D., Dawson, D. D. and Avilés, J. M. 2014. Cuckoo hosts shift from accepting to rejection parasitic eggs across their lifetime. - Evolution 68: 3020-3029. 
479

480

481

482

483

484

485

486

487

488

489

490

491

492

493

494

495

496

497

498

499

500

501

502

503

504

505

506

507

508

509

510

Møller, A. P. and Soler, M. 2012. A coevolutionary framework based on temporal and spatial ecology of host-parasite interactions: A missing link in studies of brood parasitism. - Chinese Birds 3: 259-273.

Molnár, B. 1944. The cuckoo in the Hungarian Plain. - Aquila 51: 100-112.

Moskát, C. and Honza, M. 2000. Effect of nest and nest site characteristics on the risk of cuckoo Cuculus canorus parasitism in the great reed warbler Acrocephalus arundinaceus. - Ecography 23: 335-341.

Moskát, C. and Honza, M. 2002. European cuckoo Cuculus canorus parasitism and host's rejection behaviour in a heavily parasitized great reed warbler Acrocephalus arundinaceus population. - Ibis 144: 614-622.

Moskát, C., Bán, M. and Hauber, M. E. 2014. Naïve hosts of avian brood parasites accept foreign eggs, whereas older hosts fine-tune foreign egg discrimination during laying. - Front. Zool. 11:45.

Moskát, C., Hansson, B., Barabás, L., Bártol, I. and Karcza, Z. 2008. Common cuckoo Cuculus canorus parasitism, antiparasite defence and gene flow in closely located populations of great reed warblers Acrocephalus arundinaceus. - J. Avian. Biol. 39: 663-671.

Moskát, C., Hauber, M. E., Avilés, J. A., Bán, M., Hargitai, R. and Honza, M. 2009. Increased host tolerance of multiple cuckoo eggs leads to higher fledging success of the brood parasite. - Anim. Behav. 77: 1281-1990.

Moskát, C., Takasu, F., Munoz, A. R., Nakamura, H., Bán, M. and Barta, Z. 2012. Cuckoo parasitism on two closely-related Acrocephalus warblers in distant areas: a case of parallel coevolution? - Chin. Birds 3:320-329.

Nakagawa, S. and Hauber, M. E. 2011. Great challenges with few subjects: Statistical strategies for neuroscientists. - Neurosci. Biobehav. Rev. 35: 462-473.

Nakamura, H., Kubota, S. and Suzuki, R. 1998. Coevolution between the common cuckoo and its major hosts in Japan. In: Rothstein SI, Robinson SK (eds) Parasitic birds and their hosts. Studies in coevolution. Oxford University Press, New York.

Øien, I.J., Moksnes, A. and Røskaft, E. 1995. Evolution of variation in egg color and marking pattern in European passerines: adaptations in a coevolutionary arms race with the Cuckoo, Cuculus canorus. - Behav. Ecol. 6: 166-174. 
511 Peer, B. D., Kuehn, M. J., Rothstein, S. I. and Fleischer, R. C. 2011. Persistence of

512

513

514

515

516 host defence behaviour in the absence of avian brood parasitism. - Biol. Lett. 7: 670-673.

Pozgayová, M., Procházka, P., Polaciková, L. and Honza, M. 2011. Closer clutch inspection-quicker egg ejection: timing of host responses toward parasitic eggs. - Behav. Ecol. 22: 46-51.

Procházka, P. and Honza, M. 2004. Egg discrimination in the yellowhammer. Condor 106: 405-410.

Røskaft, E. and Moksnes, A. 1998. Coevolution between brood parasites and their hosts: An optimality theory approach. In: Rothstein SI, Robinson SK (eds) Parasitic birds and their hosts. Studies in coevolution. Oxford University Press, New York.

Røskaft, E., Moksnes, A., Stokke, B. G., Moskát, C. and Honza, M. 2002. The spatial habitat structure of host populations explains the pattern of rejection behavior in hosts and parasitic adaptations in cuckoos. - Behav. Ecol. 13: 163-168.

Rothstein, S. I. 1975. An experimental and teleonomic investigation of avian brood parasitism. - Condor 77: 250-271.

Rothstein, S. I. 1990. A model system for coevolution: avian brood parasitism. - Ann. Rev. Ecol. Syst. 21:481-508.

Rothstein, S. and Robinson, S. K. 1998. The evolution and ecology of avian brood parasitism. In: Rothstein SI, Robinson SK (eds) Parasitic birds and their hosts. Studies in coevolution. Oxford University Press, New York.

Soler, M. 2014. Long-term coevolution between avian brood parasites and their hosts. - Biol. Rev. 89: 688-704.

Soler, M. and Møller, A. P. 1990. Duration of sympatry and coevolution between the great spotted cuckoo and its magpie host. - Nature 343: 748-750.

Soler, J. J. and Soler, M. 2000. Brood-parasite interactions between great spotted cuckoo and magpies: a model system for studying coevolutionary relatonships. - Oecologia 125: 309-320.

Soler, J. J., Martín-Gálvez, D., de Neve, L. and Soler, M. 2013. Brood parasitism correlates with the strength of spatial autocorrelation of life history and defensive traits in Magpies. - Ecology 94: 1338-1346.

Soler, J. J., Martínez, J. G., Soler, M. and Møller, A. P. 2001. Coevolutionary interactions in a host-parasite system. - Ecol. Lett. 4: 470-476. 
545

546

547

548

549

550

551

552

553

554

555

556

557

558

559

560

561

562

563

564

565

566

567

568

569

570

571

572

573

574

575

576

577

Soler M, Soler JJ, Martínez JG, Møller AP 1994. Micro-evolutionary change in host response to a brood parasite. - Behav. Ecol. Sociobiol. 35: 295-301.

Soler, M., Soler, J. J., Martínez, J. G., Pérez-Contreras, T. and Møller, A. P. 1998. Micro-evolutionary change and population dynamics of a brood parasite and its primary host: the intermittent arms race hypothesis. - Oecologia 117: 381390.

Stokke, B. G., Moksnes, A. and Røskaft, E. 2005. The enigma of imperfect adaptations in hosts of avian brood parasites. - Ornithol. Sci. 4: 17-29.

Stokke, B. G., Moksnes, A., Røskaft, E., Rudolfsen, G. and Honza, M. 1999. Rejection of artificial cuckoo (Cuculus canorus) eggs in relation to variation in egg appearance among reed warblers (Acrocephalus scirpaceus). - Proc. R. Soc. Lond. B 266: 1483-1488.

Stokke, B. G., Takasu, F., Moksnes, A. and Røskaft, E. 2007. The importance of clutch characteristics for antiparasite adaptations in hosts of avian brood parasites. - Evolution 61: 2212-2228.

Strausberger, B. M. and Rothstein, S. I. 2009. Parasitic cowbirds may defeat host defence by causing rejecters to misimprint on cowbird eggs. - Behav. Ecol. 20: 691-699.

Takasu, F. 1998. Modelling the arms race in avian brood parasitism. - Evol. Ecol. 12: 969-987.

Takasu F. 2003. Co-evolutionary dynamics of egg apperance in avian brood parasitism. - Evol. Ecol. Res., 5: 345-362.

Takasu, F., Kawasaki, K., Nakamura, H., Cohen, J. and Shigesada, N. 1993. Modeling the population dynamics of a cuckoo-host association and the evolution of host defenses. - Am. Nat. 142: 819-839.

Takasu, F., Moskát, C., Munoz, A. R., Imanishi, S. and Nakamura, H. 2009. Adaptations in the common cuckoo (Cuculus canorus) to host eggs in a multiple-hosts system of brood parasitism. - Biol. J. Linn. Soc. 98: 291-300.

Thorogood, R. and Davies, N. B. 2013. Reed warbler hosts fine-tune their defenses to track three decades of cuckoo decline. - Evolution 67: 3545-3555.

\section{Thompson, J. N., Nuismer, S. L. and Gomulkiewicz, R. 2002. Coevolution and} maladaptation. - Integr. and Comp. Biol. 42: 381-387. 
578 Trnka, A. and Grim, T. 2014. Testing for correlations between behaviours in a cuckoo 579 host: why do host defences not covary? - Anim. Behav. 92: 185-193.

580 Welbergen, J. A. and Davies, N. B. 2009. Strategic variation in mobbing as a front 581 line of defense against brood parasitism. - Current Biol. 19: 235e240.

582 Yamagishi, S. and Fujioka, M. 1986. Heavy brood parasitism by the common cuckoo 583 Cuculus canorus on the azure-winged magpie Cyanopica cyana. - Tori 34: 9158496.

585 Yang, C., Liu, Y., Zeng, L. and Liang, W. 2014a. Egg color variation, but not egg 586 rejection behavior, changes in a cuckoo host breeding in the absence of brood 587 parasitism. - Ecol. Evol. 4: 2239-2246.

588 Yang, C., Wang, L., Cheng, S-J., Hsu, Y-C, Stokke, B. G., Røskaft, E., Moksnes, A., 589 Liang, W. and Møller, A. P. 2014b. Deficiency in egg rejection in a host $590 \quad$ species as a response to the absence of brood parasitism. - Behav. Ecol. 26: $591 \quad 406-415$. 
593 Table 1. Parasitism rates and the relative frequency of multiple parasitism in the great 594 reed warbler.

595

\begin{tabular}{|c|c|c|c|c|c|}
\hline $\begin{array}{l}\text { Study } \\
\text { years }\end{array}$ & $\begin{array}{l}\text { Total no. } \\
\text { of nests }\end{array}$ & $\begin{array}{l}\text { Unparasitized } \\
\text { nests }\end{array}$ & $\begin{array}{l}\text { Parasitized nests } \\
\text { (total) }\end{array}$ & $\begin{array}{l}\text { Multiple } \\
\text { parasitism* }\end{array}$ & Source \\
\hline 1940 & 231 & $120(47 \%)$ & $111(53 \%)$ & $32(29 \%)$ & Molnár 1944 \\
\hline 1941 & 89 & $43(48 \%)$ & $46(52 \%)$ & $24(52 \%)$ & Molnár 1944 \\
\hline 1942 & 54 & $21(39 \%)$ & $33(61 \%)$ & $14(42 \%)$ & Molnár 1944 \\
\hline 1998 & 103 & $38(37 \%)$ & $65(63 \%)$ & $27(42 \%)$ & $\begin{array}{l}\text { Moskát \& } \\
\text { Honza } 2002\end{array}$ \\
\hline 1999 & 90 & $32(36 \%)$ & $58(64 \%)$ & $17(29 \%)$ & $\begin{array}{l}\text { Moskát \& } \\
\text { Honza } 2002\end{array}$ \\
\hline 2006 & 54 & $26(46 \%)$ & $29(54 \%)$ & $7(24 \%)$ & present study \\
\hline 2007 & 50 & $20(43 \%)$ & $26(57 \%)$ & $7(27 \%)$ & present study \\
\hline
\end{tabular}


598 Table 2. Number of non-parasitized, single and multiple parasitized nests. Multiple 599 parasitism is shown in categories of cuckoo eggs in clutch. (Please take note of the

600 uneven sizes of the study areas in the Apaj site, related to reed quality and intensity of 601 the study.)

602

\begin{tabular}{|c|c|c|c|}
\hline $\begin{array}{l}\text { No. of } \\
\text { cuckoo } \\
\text { eggs per } \\
\text { clutch }\end{array}$ & $\begin{array}{l}\text { Szarvas 1940- } \\
1942 \\
\text { (Molnár 1944) }\end{array}$ & $\begin{array}{l}\text { Apaj 1998- } \\
1999 \\
\text { (Moskát \& } \\
\text { Honza 2002) }\end{array}$ & $\begin{array}{l}\text { Apaj 2006- } \\
2007 \\
\text { (present study) }\end{array}$ \\
\hline 0 & $114(37.4 \%)$ & $70(36.3 \%)$ & $50(48.1 \%)$ \\
\hline 1 & $121(39.7 \%)$ & $79(40.9 \%)$ & $40(38.5 \%)$ \\
\hline 2 & $50(16.4 \%)$ & $28(14.5 \%)$ & $10(9.6 \%)$ \\
\hline 3 & $17(5.6 \%)$ & $12(6.2 \%)$ & $3(2.9 \%)$ \\
\hline 4 & $2(0.6 \%)$ & $4(2.1 \%)$ & $1(0.9 \%)$ \\
\hline 5 & $1(0.3 \%)$ & $0(0 \%)$ & $0(0 \%)$ \\
\hline
\end{tabular}

603

604

605 
606 Table 3. Great reed warblers' responses toward cuckoo eggs in instances of single and 607 multiple parasitism.

608

\begin{tabular}{|c|c|c|c|c|c|}
\hline & \multicolumn{5}{|c|}{ Host responses } \\
\hline & Acceptance & Rejection* & Ejection & Desertion & Burial \\
\hline \multicolumn{6}{|c|}{ Szarvas 1940-1942 (Molnár 1944) } \\
\hline Single & $33(59 \%)$ & $23(41 \%)$ & 8 & 7 & 8 \\
\hline Multiple & $68(71 \%)$ & $28(29 \%)$ & 4 & 15 & 9 \\
\hline All & $101(66 \%)$ & $51(34 \%)$ & 12 & 223 & 17 \\
\hline
\end{tabular}

Apaj 1998-1999 (Moskát \& Honza 2002)

\begin{tabular}{lccccc}
\hline Single & $41(58 \%)$ & $30(42 \%)$ & 13 & 14 & 3 \\
Multiple & $67(73 \%)$ & $25(27 \%)$ & 6 & 18 & 1 \\
All & $108(66 \%)$ & $55(34 \%)$ & 19 & 32 & 4 \\
\hline \multicolumn{2}{l}{ Apaj 2006-2007 (present study) } & & & \\
\hline Single & $20(57 \%)$ & $15(43 \%)$ & 11 & 3 & 1 \\
Multiple & $17(65 \%)$ & $9(35 \%)$ & 3 & 6 & 0 \\
All & $37(61 \%)$ & $24(39 \%)$ & 14 & 9 & 1
\end{tabular}

$609{ }^{*}$ Including egg ejections, nest desertions and egg burials.

610

611

612

613

614

615 
616 Legend to the figures

617

618

619 Figure 1 Mean values of common cuckoo parasitism on great reed warblers in three

620 study periods (1940-42, 1998-99, and 2006-2007) in Hungary. (Parasitism rate =

621 percent of parasitized nests, multiple parasitism = percent of parasitized nests which

622 contained more than one cuckoo egg, rejection rate in single parasitism = percent of

623 cuckoo eggs rejected by egg ejection, nest desertion or egg burial, and rejection rate in

624 multiple parasitism = percent of cuckoo eggs rejected by ejection, desertion or egg

625 burial.) 


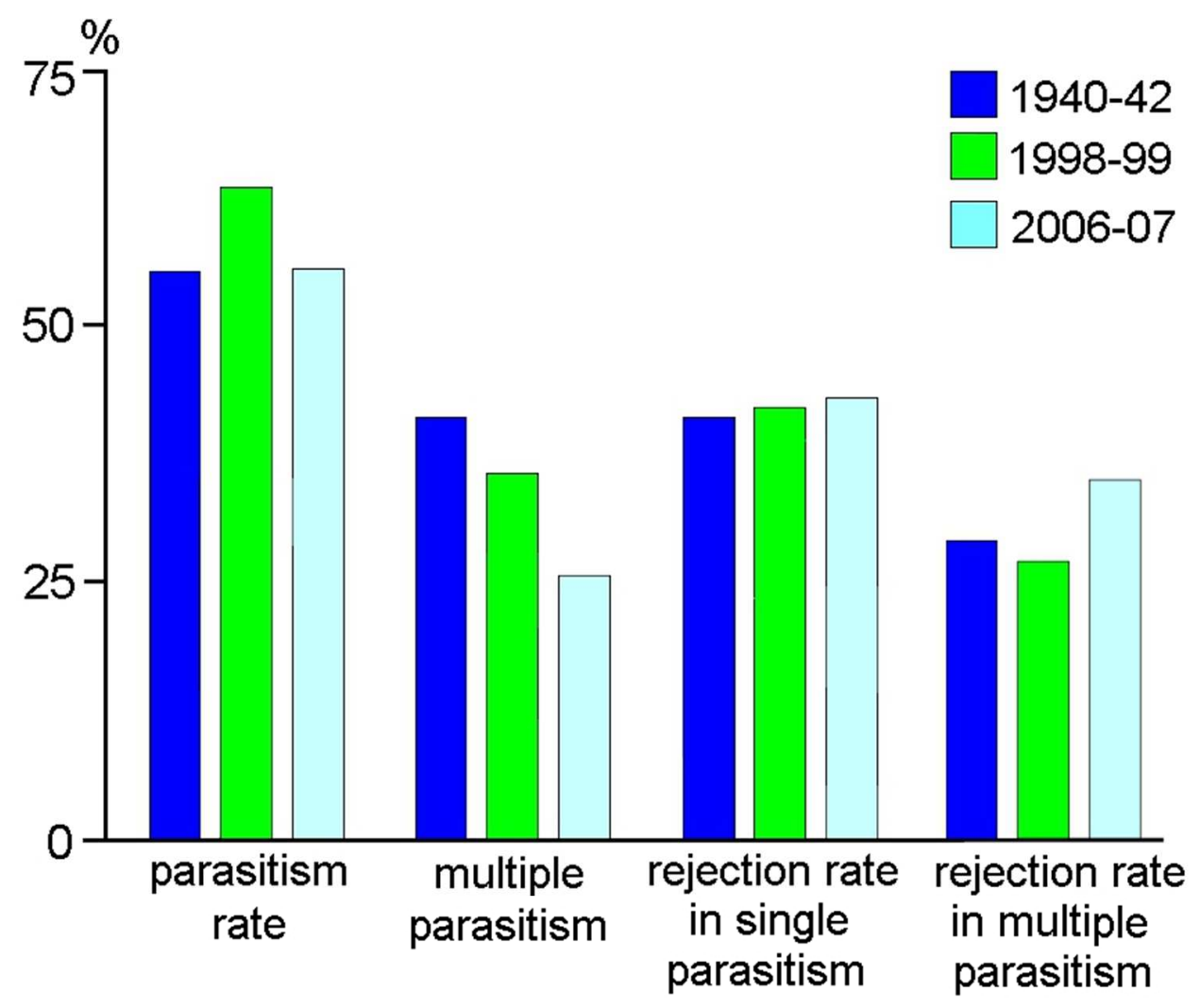

Figure 1 Mean values of common cuckoo parasitism on great reed warblers in three study periods (1940-42, 1998-99, and 2006-2007) in Hungary. (Parasitism rate = percent of parasitized nests, multiple parasitism $=$ percent of parasitized nests which contained more than one cuckoo egg, rejection rate in single parasitism $=$ percent of cuckoo eggs rejected by egg ejection, nest desertion or egg burial, and rejection rate in multiple parasitism = percent of cuckoo eggs rejected by ejection, desertion or egg burial.)

$75 \times 62 \mathrm{~mm}(300 \times 300 \mathrm{DPI})$ 